\title{
Shadow Price of the Oil Industry
}

\author{
LIU XiMei; WANG ChangFeng; Shahid Rasheed and Muhammad Nawaz Tunio \\ School of Economics and Management, Beijing University of Posts and \\ Telecommunications, Beijing 1000876, China \\ 1092457487@qq.com;wangcf@bupt.edu.cn;shahidrasheed@outlook.com; \\ mntunio2014@hotmail.com
}

\begin{abstract}
Oil, hailed as modern industrial blood, is of greater significance to a state, and is closely related to people's lives. Shadow price of the oil industry is a key evaluation parameter for the business of an economy. In this paper, the application of input-output method and linear programming theory has been sought to establish an optimization model for the oil industry and the shadow price of the oil industry has been calculated according to the 2007 China input-output table. The analysis concludes that among the agriculture, the industry, and the tertiary industry, the prices of oil industry products bear maximum influence on the prices of agricultural products.
\end{abstract}

Key words: input-output model; linear programming; shadow price; oil industry

\section{Introduction}

In today's world, oil is recognized as the "blood" of a national economy. It is not only an imperative strategic resource for energy but is also an important chemical raw material. A lot of studies have been dedicated to evaluate the social benefits of oil industry and various useful conclusions are also drawn. Shadow price in operations research is defined as the optimal solution to the dual problem [1].

In year 2002, Yu Bo, Chi Chunjie, and Su Guofu used input-output model analysis to calculate the impact of oil price fluctuations on China's economy [2]. Similarly, in 2004, Han Dongyan and Chen Rui analyzed the influence of petroleum price on national economy equilibrium and the impact of oil price fluctuations on rest of the industry, and put forward certain countermeasures and Suggestions [3]. In 2007, Liu Weiguo, Xu Wenxin, and Li Xiaoliang used logit function to monitor the degree to which the changes in oil prices impact the economy [4]. Likewise, in 2008, Li Yunling conducted an empirical analysis by applying the input and output method to work out the effect of oil industry on the other industry in China. He suggested some policy recommendations for China's petroleum import and export trade and energy consumption [5]. In year 2010, Li Xiaoyan used grey correlation to establish three models for quantitative analysis of correlation between energy consumption and economic growth. Based on his findings, he advanced the implementation of energy saving measures in order to improve the efficiency of energy utilization [6]. More recently in year 2015, Song Bo and Mu Yueying proposed a new method to deduce the shadow price of carbon emission based on the parameterized environmental directional distance function [7]. Also in year 2015, Tian Shiqiang, Shi Guangming, and Xiong Hui analyzed the shadow price of sulfur dioxide and nitrogen oxide by using the pollutant emission data of 23 thermal power plants in Hunan province [8].

Since the mentioned studies rarely dealt with the shadow price of petroleum industry, they can hardly be used directly for evaluation of oil industry's impact on the national economy. The development of market economy in China, the strengthening of macro-control, and the declining oil prices in Chinese industry make it increasingly 
important for the policy makers to research on the shadow price of the oil industry.

Shadow Price in a strict mathematical concept can be obtained from linear programming. The linear programming can be used to derive the largest output under resource constraints; the solution is the optimal allocation of resources i.e., the optimal Price (i.e., Shadow Price). The economic meaning of Shadow Price is the resource's marginal opportunity cost [9-12].

\section{Calculation Method for the Shadow Price of Oil Industry}

\subsection{Related Statistics Index and Output Table [13]}

This research mainly involves three national economic statistical indicators: Social Output or Gross State Product (GSP), Gross National Product (GNP), and National Income (NI). The input-output table has three corresponding statistics: Output, Final Use, and Living. In the input-output table, living inputs include labor remuneration, net taxes, and operating surplus production. Investment inputs are divided into the initial, intermediate, and the total investment. Their relationships are given as follows.

primary input $=$ depreciation of fixed assets + living for initial input

Total $=$ initial input + intermediate input

According to the input and output balance theory, there is

$\sum$ industry output $=\sum$ industry investment

$\sum$ initial input $=\sum$ industry eventually uses

The oil industry holds an important position within the whole system of input and output of the national economy. In this paper, we will analyze the impact of per unit increment of the oil industry price on the overall GSP, GNP, and NI of Chinese Economy.

The 2007 China input-output table with merged statistics is shown below (See Table 1), where the oil sector includes: oil and gas drilling and processing, and coking and nuclear fuel processing. The source of this Table is [14].

Table 1. 2007 China Input-Output for 4 Industries [15-17]

\begin{tabular}{|c|c|c|c|c|c|c|c|}
\hline & \multicolumn{4}{|c|}{ Intermediate Use } & \multirow[b]{2}{*}{$\begin{array}{l}\text { The } \\
\text { Eventually } \\
\text { Use }\end{array}$} & \multirow[b]{2}{*}{$\begin{array}{l}\text { The Total } \\
\text { Output }\end{array}$} \\
\hline & & $\begin{array}{l}\text { Agriculture } \\
\text { Industry }\end{array}$ & $\begin{array}{l}\text { Oil } \\
\text { Industr } \\
\mathrm{y}\end{array}$ & $\begin{array}{l}\text { Industr } \\
\mathrm{y}\end{array}$ & $\begin{array}{l}\text { The Tertiary } \\
\text { Industry }\end{array}$ & & \\
\hline \multirow{4}{*}{$\begin{array}{l}\text { Interm } \\
\text { ediate } \\
\text { Input }\end{array}$} & $\begin{array}{l}\text { Agriculture } \\
\text { Industry }\end{array}$ & 68771565 & 6543 & $\begin{array}{c}24916 \\
1123\end{array}$ & 25500448 & 145490320 & $\begin{array}{c}48893000 \\
0\end{array}$ \\
\hline & Oil Industry & 3956136 & $\begin{array}{c}13593 \\
4997\end{array}$ & $\begin{array}{c}15173 \\
0743\end{array}$ & 78399288 & -63926648 & $\begin{array}{c}30609451 \\
6\end{array}$ \\
\hline & Industry & 98640362 & $\begin{array}{c}55714 \\
338 \\
\end{array}$ & $\begin{array}{l}33044 \\
52245 \\
\end{array}$ & 403735456 & $\begin{array}{c}160717156 \\
3 \\
\end{array}$ & $\begin{array}{c}54697139 \\
64 \\
\end{array}$ \\
\hline & $\begin{array}{l}\text { The Tertiary } \\
\text { Industry }\end{array}$ & 30970198 & $\begin{array}{c}19951 \\
374 \\
\end{array}$ & $\begin{array}{c}51390 \\
4317 \\
\end{array}$ & 387322375 & 971702875 & $\begin{array}{c}19238511 \\
39 \\
\end{array}$ \\
\hline \multirow{4}{*}{$\begin{array}{l}\text { The } \\
\text { Total } \\
\text { Initial } \\
\text { Input }\end{array}$} & $\begin{array}{l}\text { The Laborers } \\
\text { Remuneration }\end{array}$ & $\begin{array}{c}2718 \\
1627 \\
0\end{array}$ & $\begin{array}{c}24005 \\
801\end{array}$ & $\begin{array}{c}43593 \\
6123\end{array}$ & 368714806 & & \\
\hline & $\begin{array}{l}\text { Net Taxes } \\
\text { on Production }\end{array}$ & 478020 & $\begin{array}{c}22325 \\
315 \\
\end{array}$ & $\begin{array}{c}24777 \\
7588 \\
\end{array}$ & 114606310 & & \\
\hline & $\begin{array}{l}\text { The Depreciation o } \\
\text { f Fixed Assets }\end{array}$ & 14297448 & $\begin{array}{c}12964 \\
582 \\
\end{array}$ & $\begin{array}{c}16865 \\
2656 \\
\end{array}$ & 176640636 & & \\
\hline & Operating Surplus & 0 & $\begin{array}{c}35191 \\
566\end{array}$ & $\begin{array}{c}39809 \\
9170 \\
\end{array}$ & 368931819 & & \\
\hline \multicolumn{2}{|c|}{ The Total Input } & 488930000 & $\begin{array}{c}30609 \\
4516 \\
\end{array}$ & $\begin{array}{l}54697 \\
13964 \\
\end{array}$ & 1923851139 & & \\
\hline
\end{tabular}

\subsection{The Optimization Model of National Economic Structure}


In order to get the shadow price of petroleum industry, the optimization model for national economic structure is given as follows [18-21]

$$
\begin{aligned}
& \max C Y \\
& \text { s.t. }\left\{\begin{array}{l}
(\mathrm{I}-A)^{-1} Y \leq X_{u p} \\
Y \geq Y_{\text {low }}
\end{array}\right.
\end{aligned}
$$

In this model $C$ is the row vector for the value coefficient while $Y$ is the decision variable showing the end product column vector for each industry. $A$ is direct consumption coefficient matrix of the input and output, I is the unit matrix, $(\mathrm{I}-A)^{-1}$ is the inverse matrix of input and output. Moreover, $X_{u p}$ is maximum output column for each industry which is a resource constraint and reflects the restriction of national economic development ability while $Y_{\text {low }}$ is the column for final production output of each industry which is a constraint and reflects the fundamental guarantee of maintaining consumer and reproduction.

According to the linear programming theory, in the condition of the optimal solution, the opportunity cost of each resource slack variable is the resource shadow price $q_{j}$. The definition of shadow price $q_{j}$ unit depends on the value of the coefficient $C$. For the 3 kinds of national economic evaluation indicators that were mentioned in section 2.2, $G S P_{i}$ is the output of the industry $i, G N P_{i}$ is the final product of the industry $i, P I_{i}$ is the initial input of the industry $i$, and $N I_{i}$ is the living of the industry. We have the following three ways to define the coefficient $C$ :

When we view GSP as evaluation index expressed as $C_{G S P}$, its weight is: $C_{i}=G S P_{i} / G N P_{i}$

When we view $G N P$ as evaluation index expressed as $C_{G N P}$, its weight is: $C_{i}=P I_{i} / G N P_{i}$

When we view $N I$ as evaluation index expressed as $C_{N I}$, its weight is: $C_{i}=N I_{i} / G N P_{i}$

For model (1) the value of coefficient ${ }^{C}$ can also be given other definitions, but the said three ways bear the following advantages:

1. Economic meaning is clear. It is more practical as a conversion factor for the conversion of the final product value of each industry into the evaluation index of the national economy;

2. To a certain extent reflects the extent to which an industry lacks in the final product, because $C_{i}$ is inversely proportional to $Y_{i}$.

Model (1) can be further simplified [22]:

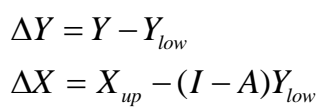

\section{So}

$\max C \Delta Y$

s.t. $\left\{\begin{array}{l}(\mathrm{I}-A)^{-1} \Delta Y \leq \Delta X \\ \Delta Y \geq 0\end{array}\right.$

\subsection{The Calculation Method of Shadow Price of Oil Industry}

When calculating the shadow price of petroleum industry, in order to eliminate the effect of other industries we should fix the output of other industries. In effect, we keep the growth rate of other industries as fixed while the growth rate of the industry under 
evaluation (i.e., Oil industry) as variable.

When growth rate of the evaluation industry and $Y_{\text {low }}$ are changed, the optimal solution of linear programming model (1) may have two states [22]:

1. When, for the oil industry, the $\Delta Y_{i}=0$, the optimal solution can be found in the slack variable of the other industry; the shadow price of the oil industry at such time is very high and industry is in the status of "shortage";

2. When the optimal solution is found in the slack variable of the oil industry, the shadow price of the industry is zero, leading it to the status of "overcapacity".

When calculating the shadow price of petroleum industry, the state 1 only needs to be solved with linear programming. When the oil industry faces "overproduction", the shadow price is 0 and does not needs to be solved with linear programming.

The steps for shadow price calculation for the oil industry are as follows:

Step 1: Sort out input-output table and calculate matrix $A,(I-A)$, and ${ }^{(I-A)^{-1}}$. Simultaneously obtain the final use vector $Y_{B}$ and total output vector $X_{B}$ (for four industries) of year 2007 from Table 1.

Step 2: According to the Chinese statistical yearbook, we should calculate the pace ${ }^{r_{g}}$ of each industry.

$$
R=\left[\begin{array}{ccc}
r_{1} & \cdots & 0 \\
\cdots & r_{2} & \cdots \\
0 & \cdots & r_{m}
\end{array}\right]
$$

Step 3: For the given value ${ }^{r_{g}}$ against each industry, calculate $X_{u p}=(I+R) X_{B}$; then fix $Y_{\text {low }}$ and calculate $\Delta X=X_{\text {up }}-(I-A)^{-1} Y_{\text {low }}$;

Step 4: Calculate ${ }^{\Delta Y=(I-A) \Delta X}$

As $r_{k}$ or $Y_{\text {low }}$ changes from smaller to larger value, the following two states may appear:

1. If $\Delta y_{k}<0$, the $k$ industry is in a state of "serious shortage". By solving the linear programming model (1) for the optimal solutions, we can obtain the shadow price of the ${ }^{k}$ industry;

2. If $\Delta y_{i}<0, i \neq k$, the $k$ industry is in a state of "over production" and the shadow price is 0 .

\section{The Empirical Analysis of Shadow Price of Oil Industry}

\subsection{Fundamental Analysis}

The first kind of circumstance:

Possibility 1: If $Y_{\text {low }}=0.7 Y_{B}, r_{2}=10 \%$

The speed of industry is obtained from the statistical yearbook, as follows [14]:

$r_{1}=6.8 \%, r_{3}=18 \%, r_{4}=13 \%$

From table 1 we get:

$A=\left[\begin{array}{llll}0.1407 & 0.0000 & 0.0456 & 0.0133 \\ 0.0081 & 0.4441 & 0.0277 & 0.0408 \\ 0.2017 & 0.1820 & 0.6041 & 0.2099 \\ 0.0633 & 0.0652 & 0.0940 & 0.2013\end{array}\right]$

From analysis of the second part we obtain: 
$\Delta y=\left[\begin{array}{c}23635750.5891 \\ -39787549.9949 \\ 807306669.2330 \\ 394435688.9664\end{array}\right]$

Condition 1: 2 (oil) industry is in a state of "shortage"; by solving the linear programming the optimal solution of (1) type, can give the shadow price of oil industry. The calculation process is in part 3.

The second kind of circumstance:

Possibility 2: If $Y_{\text {low }}=Y_{B}, r_{2}=10 \%$

Following can be obtained by analysis of the second part:

$\Delta y=\left[\begin{array}{c}-20011345.41 \\ -20609555.59 \\ 325155200.3 \\ 102924826.5\end{array}\right]$

Condition 2: 2 (oil) industry product is in a state of "overproduction", so the shadow price of petroleum industry is 0 .

\subsection{Mathematical Model and Its Solution}

$$
\text { When } Y_{\text {low }}=0.7 Y_{B}, r_{2}=10 \%
$$

\subsubsection{The Evaluation Index is GSP:}

$C=\left[\begin{array}{lllll}3.360567207 & -4.78821 & 3.403317 & 1.979876\end{array}\right]$

The model is as follows:

Objective function:

$\max z=3.360567207 y_{1}-4.78821 y_{2}+3.403317 y_{3}+1.97986 y_{4}$

Constraint condition:

$$
\begin{aligned}
& 1.2063 y_{1}+0.0595 y_{2}+0.1585 y_{3}+0.0648 y_{4}<=522177240 \\
& 0.0686 y_{1}+1.8721 y_{2}+0.1726 y_{3}+0.1421 y_{4}<=336703967.6 \\
& 0.7463 y_{1}+1.0393 y_{2}+2.8798 y_{3}+0.8223 y_{4}<=6454262478 \\
& 0.1890 y_{1}+0.2799 y_{2}+0.3656 y_{3}+1.3656 y_{4}<=2173951787 \\
& y_{1}>=101843224 ; \\
& y_{2}>=-44748653.6 ; \\
& y_{3}>=1125020094 ; \\
& y_{4}>=680192012.5 ; \\
& \text { Model results: } \\
& q=18.10517
\end{aligned}
$$

The total results:

Table 2. The Total Results when Evaluation Index is GSP

\begin{tabular}{|r|r|}
\hline The Growth Rate of $\boldsymbol{r}_{2}$ & The Shadow Price of Oil Industry \\
\hline 0 & 48.98786 \\
\hline 10 & 18.10517 \\
\hline 20 & 18.10517 \\
\hline 30 & 18.10517 \\
\hline 40 & 18.10517 \\
\hline 50 & 10.45846 \\
\hline 60 & 0 \\
\hline
\end{tabular}




\begin{tabular}{|r|r|}
\hline 70 & 0 \\
\hline 80 & 0 \\
\hline 90 & 0 \\
\hline 100 & 0 \\
\hline
\end{tabular}

The general model results curve:

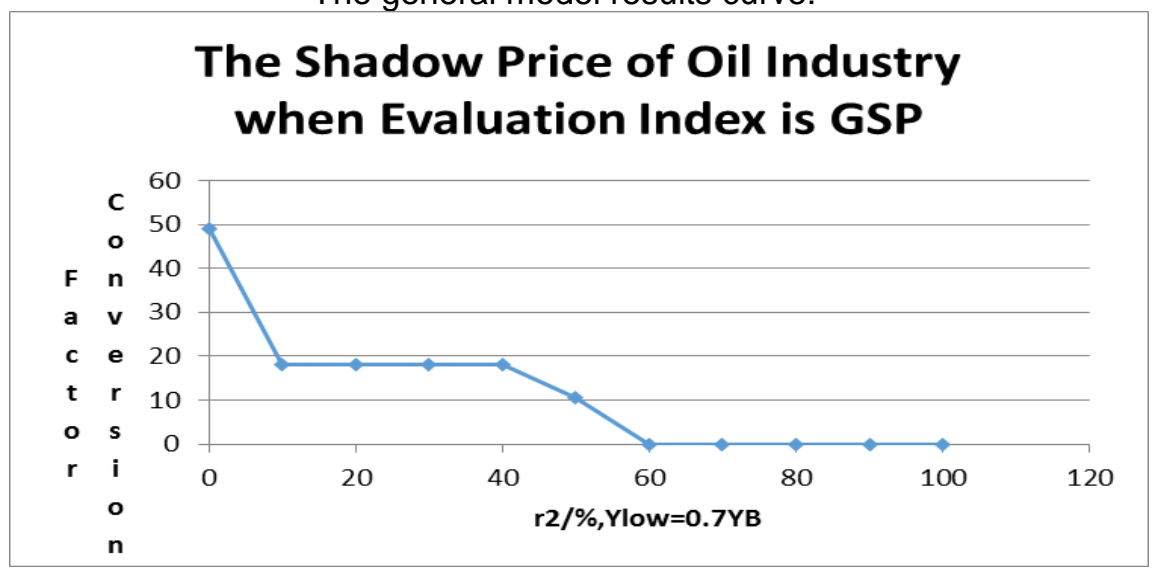

Figure 1. The Shadow Price of Oil Industry when Evaluation Index is GSP

We infer that when the Evaluation Index is GSP and $Y_{\text {low }}=0.7 Y_{B}$, with the increase of the speed of oil industry, the shadow price of oil industry is gradually diminishing.

\subsubsection{The Evaluation Index is GNP:}

$C=\left[\begin{array}{llll}1.96983371 & -1.478057544 & 0.778053548 & 1.058856156\end{array}\right]$

The model is as follows:

Objective function:

$\max z=1.96983371 y_{1}-1.478057544 y_{2}+0.778053548 y_{3}+1.058856156 y_{4}$

Constraint condition:

$1.2063 y_{1}+0.0595 y_{2}+0.1585 y_{3}+0.0648 y_{4}<=5221772456$

$0.0686 y_{1}+1.8721 y_{2}+0.1726 y_{3}+0.1421 y_{4}<=336703967.6$

$0.7463 y_{1}+1.0393 y_{2}+2.8798 y_{3}+0.8223 y_{4}<=6454262478$

$0.1890 y_{1}+0.2799 y_{2}+0.3656 y_{3}+1.3656 y_{4}<=2173951787$

$y_{1}>=101843224$

$y_{2}>=-44748653.6$

$y_{3}>=1125020094$

$y_{4}>=680192012.5$

Model results:

$q=6.885388$

The total results:

Table 3. The Total Results when Evaluation Index is GNP

\begin{tabular}{|r|r|}
\hline The Growth Rate of $\boldsymbol{r}_{2}$ & The Shadow Price of Oil Industry \\
\hline 0 & 6.885388 \\
\hline 10 & 6.885388 \\
\hline 20 & 6.885388 \\
\hline 30 & 2.171245 \\
\hline 40 & 2.171245 \\
\hline
\end{tabular}




\begin{tabular}{|r|r|}
\hline 50 & 2.171245 \\
\hline 60 & 0 \\
\hline 70 & 0 \\
\hline 80 & 0 \\
\hline 90 & 0 \\
\hline 100 & 0 \\
\hline
\end{tabular}

The general model results curve

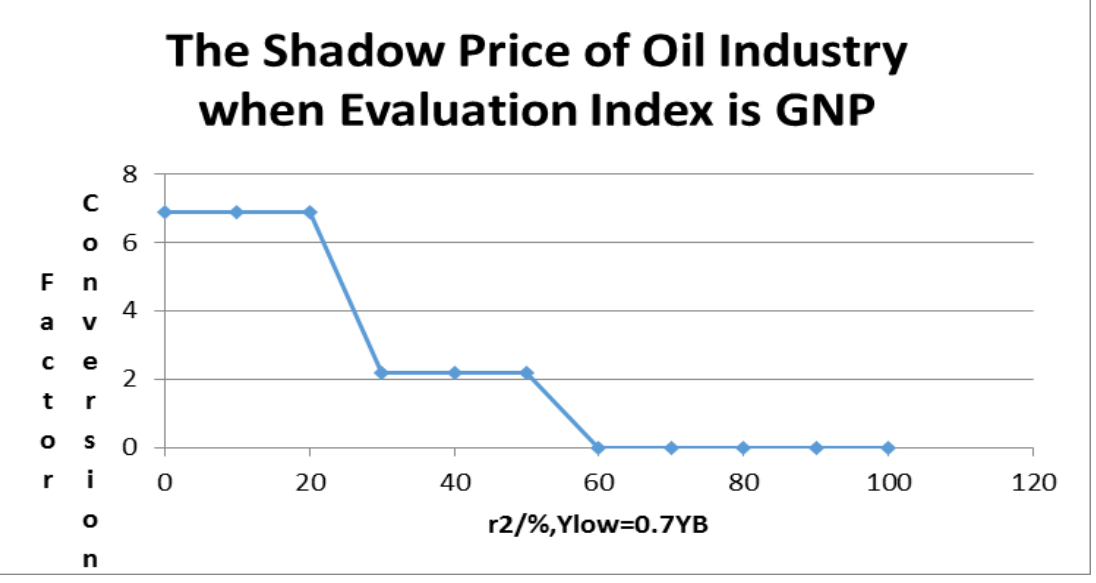

Figure 2. The Shadow Price of Oil Industry when Evaluation Index is GNP

We infer that when the Evaluation Index is GNP and $Y_{\text {low }}=0.7 Y_{B}$, with the increase of the speed of oil industry, the shadow price of oil industry is gradually diminishing.

\subsubsection{The Evaluation Index is NI:}

$C=\left[\begin{array}{llll}1.96654813 & -1.12882423 & 0.62388358 & 0.94091238\end{array}\right]$

The model is as follows:

Objective function:

$\max z=1.96654813 y_{1}-1.12882423 y_{2}+0.62388358 y_{3}+0.94091238 y_{4}$

Constraint condition:

$1.2063 y 1+0.0595 y_{2}+0.1585 y_{3}+0.0648 y_{4}<=522177240$

$0.0686 y_{1}+1.8721 y_{2}+0.1726 y_{3}+0.1421 y_{4}<=336703967.6$

$0.7463 y_{1}+1.0393 y_{2}+2.8798 y_{3}+0.8223 y_{4}<=6454262478$

$0.1890 y_{1}+0.2799 y_{2}+0.3656 y_{3}+1.3656 y_{4}<=2173951787$

$y_{1}>=101843224$

$y_{2}>=-44748653.6$

$y_{3}>=1125020094$

$y_{4}>=680192012.5$

Model results:

$$
q=6.034561
$$

The total results:

Table 4. The Total Results when Evaluation Index is NI

\begin{tabular}{|r|r|}
\hline The Growth Rate of $\mathbf{r}_{2}$ & The Shadow Price of Oil Industry \\
\hline 0 & 28.66688 \\
\hline 10 & 6.034561 \\
\hline 20 & 6.034561 \\
\hline
\end{tabular}




\begin{tabular}{|r|r|}
\hline 30 & 1.207407 \\
\hline 40 & 1.207407 \\
\hline 50 & 1.207407 \\
\hline 60 & 0 \\
\hline 70 & 0 \\
\hline 80 & 0 \\
\hline 90 & 0 \\
\hline 100 & 0 \\
\hline
\end{tabular}

The general model results curve:

\section{The Shadow Price of Oil Industry when Evaluation Index is NI}

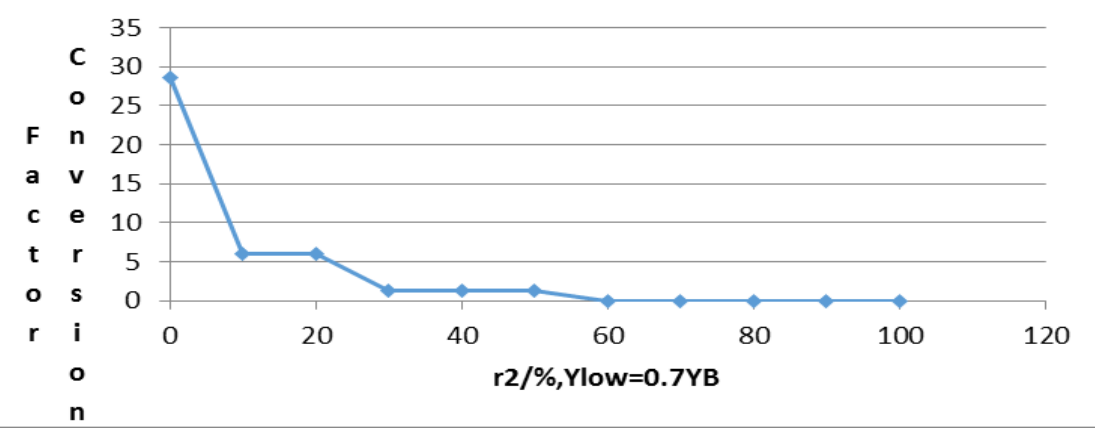

Figure 3. The Shadow Price of Oil Industry when Evaluation Index is NI

We infer that when the Evaluation Index is NI and $Y_{\text {low }}=0.7 Y_{B}$, with the increase of the speed of oil industry, the shadow price of oil industry is gradually diminishing.

\section{The Total Result Analysis}

After calculations, we can get that: when $Y_{\text {low }}=0 \sim 0.86 Y_{B}$, with the increase of the speed of oil industry, shadow price of oil industry is gradually diminishing;

When $Y_{\text {low }}=0.87 Y_{B} \sim Y_{B}$, with the increase of the speed of oil industry, shadow price of oil industry is 0 .

\section{Empirical Analysis of Product Price Influence of Oil Industry on Other Industries}

From the above analysis, we can obtain the following:

$$
B=(I-A)^{-1}=\left[\begin{array}{rrrr}
1.20627 & 0.059483 & 0.15848 & 0.064774 \\
0.068641 & 1.872078 & 0.17264 & 0.142145 \\
0.746343 & 1.039296 & 2.879823 & 0.822342 \\
0.189043 & 0.279853 & 0.365583 & 1.365554
\end{array}\right]
$$

When the oil industry prices have risen $10 \%$, then the other industries product prices have raised too [23]:

$$
\left[\begin{array}{c}
\Delta p_{1} \\
\Delta p_{3} \\
\Delta p_{4}
\end{array}\right]=\left[\begin{array}{l}
b_{11} / b_{12} \\
b_{13} / b_{12} \\
b_{14} / b_{12}
\end{array}\right] \times 10 \%=\left[\begin{array}{l}
2.027923 \\
0.266430 \\
0.108896
\end{array}\right]
$$

From the above analysis, it can be obtained that among the agriculture, the industry, and the tertiary industry, the prices of oil industry products have the biggest influence on the prices of agricultural products; the rate of fluctuation affect is $2.027923 \%$, which 
reflects more dependence of agriculture on the oil industry.

\section{Conclusions}

At first, this paper manipulates the 2007 input-output table to get input-output table that only have agriculture industry, oil industry, the industry, and the tertiary industry. Then we establish national economy optimization model based on the oil industry and list the steps to solving the model. Finally, we empirically analyze the shadow price of the oil industry based on the optimization model. We find that changes in the price of the oil industry have the greatest influence on the prices of agricultural products. The industry positions next in respect of such influence while the tertiary industry stands at the last. Our results follow that 1) when $Y_{\text {low }}=0 \sim 0.86 Y_{B}$, with the increase of the speed of oil industry, shadow price of oil industry is gradually diminishing, and 2) when $Y_{\text {low }}=0.87 Y_{B} \sim Y_{B}$, with the increase of the speed of oil industry, shadow price of oil industry is 0 . Lastly, the empirical analysis of product price influence of oil industry on other industries shows an increased dependence of the agriculture on the oil industry.

\section{References}

[1] M. Lianying, S. Huimin, P. Shiyou and Y. Xiangjuan, "Discussion on the Shadow Price of Resources," Education Modernization, no. 12, (2015), pp. 169-172.

[2] Y. Bo, C. Chunjie and S. Guofu,"Oil Prices Impact on the National Economy Measure Model, ” Journal of Quantitative \& Technical Economics, no. 5, (2002), pp. 74-76.

[3] H. Dongyan and C. Rui, "Influence of Petroleum Price Fluctuation on China's National Economy," Commercial Research, vol. 14, no. 050, (2004), pp. 135-138.

[4] L.Weiguo, X. Wenxin and L. Xiaoliang,"Study on the Influence of Oil Price Change to China Economy by Inspection Model, ”Journal of Beijing Institute of Petro-chemical T echnology, vol. 15, no. 4, (2007), pp. 57-60.

[5] L. Yunling,"Look From the Oil to the Role of the National Economy of China's Oil Import and Export Trade," Economic and Trade Forum, no. 7, (2008), pp. 12-14.

[6] L. Xiaoyan,"Analysis of Relationship between Energy Consumption and Economic Growth Based on Gray Relevance," Journal of Chongqing Univercity(Social Science Edition), vol. 16, no. 5, (2010), pp. 31-35.

[7] S. Bo and M. Yueying, "The Shadow Price of Carbon Emission in Vegetable Production in China," Journal of Agrotechnical Economics, no. 8, (2015), pp. 53-63.

[8] T. Shiqiang, S. Guangming and X. Hui, "Study on the Shadow Price of Pollutant Emission from Thermal Power Enterprises in Hunan Province," Environment and Sustainable Development, no. 5, (2015), pp.53-57.

[9] H. Jing and C. Xikang, "Calculation of Chinese Shadow Price of Water Resource Based on Dynamic Computable Equilibrium Models, ”Systems Engineering-Theory\&Practice, no. 5, (2005), pp. 49-54.

[10] Y. Peng and C. Shi, "Estimating Shadow Pricing of Industrial Pollutions in China, "Statistical Research, vol. 28, no. 9, (2011), pp. 66-73.

[11] L. Xiuli and Z. Cui, "Calculating and Forecasting Shadow Prices of All Kinds of Water in China and Its Nine Major River Basins, ”Advances in Science and Technology of Water Resources, vol. 34, no. 4, (2014), pp. 10-15.

[12] L. Qining, Y. Ruijin, X. Zhanhong and K. Guoqiang, "The Shortage Degree and National Economy Benifit of Posts and Telecommunications, " Journal of Beijing Universityof Posts and Telecommunications, vol. 17, no. 4, (1994), pp. 35-40.

[13] C. Xikang, L. Qiyun and Q. Shuchang, "Take Up Input-Output Table on Water Conservancy Establishment and Application, "Statisical Policy, no. 8, (2003), pp. 10-13.

[14] The National Bureau of Statistics of the People's Republic of China, http://www.stats.gov.cn/.

[15] R. Zeping and P. Wenqing, "Crude Oil Price Effects on China's Price Level Based on Input-output Price Model, "Statistical Research, vol. 24, no. 11, (2007), pp. 22-28.

[16] L. Xiuting, L. Fan and W. Di, "Exploring the Role of the Real Estate Sector in the Chinese Economy:1997-2007 , "Systems Engineering-Theory \&Practice, vol. 32, no. 4, (2014), pp. 323-336.

[17] S. Lisheng and W. Zhenyu, "The Contribution to Economic Growth From Export in China-Empirical Analysis Based on the IPO Table, "Economic Research Journal, no. 11, (2003), pp. 33-41.

[18] Y. Qi, "Maximum Satisfy the Constraint Conditions of the Linear Programming Model, " Journal of Dalian Institute of Light Industry, vol. 8, no. 4, (1989), pp. 81-85.

[19] X. Yan, "Logistics Supplier Selection Using Fuzzy Multi-objective Linear Programming with Considering Carbon Emission, "Sci-tech, no. 1, (2015), pp. 143-147. 
[20] X. Chunshan, "Optimization Scheduling Model of City Traffic Flow Based on Linear Programming, "Control Engineering of China, vol. 21, no. 4, (2014), pp. 143-147.

[21] D. Dawei, "Linear Programming Model in the Application of Economic Management, "Journal of Mudanjiang Normal University, no. 1, (2014), pp. 3-4.

[22] X. Zhanhong, K. Guoqiang, L. Qining and Y. Ruijin, "Study of Shadow Price for Posts and Telecommunications Product, "Journal of Beijing Universityof Posts and Telecommunications, vol. 18, no. 4, (1995), pp. 25-31.

[23] Z. Huaming and S. Peimin, "A Study on the Relationship between China's Output, Monetary Policy and Energy Price,”Shanxi University of Finance\&Econimics, (2012), pp. 76-83.

\section{Authors}
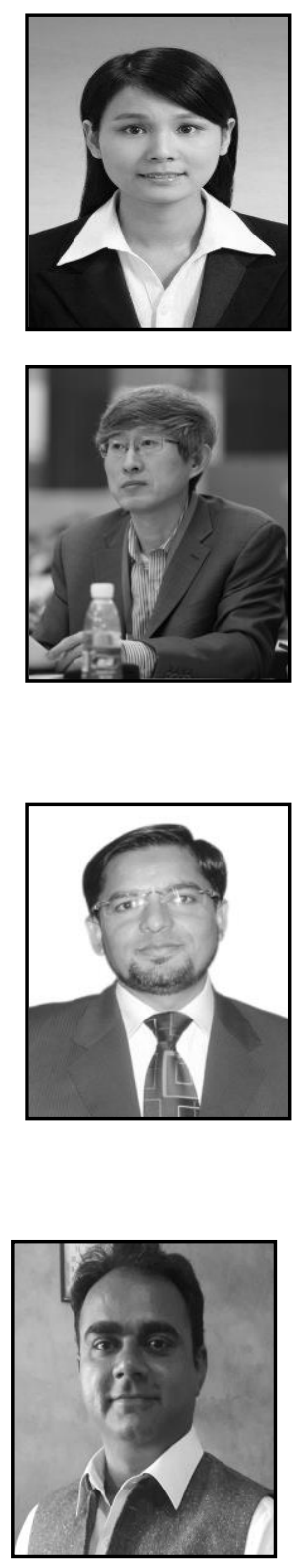

Muhammad Nawaz Tunio, Mr. Tunio is a PhD Scholar at School of Economics and Management in Beijing University of Posts and Telecommunications. Mr. Tunio has done MS in Science and Technology Policy. His research areas include ICT \& Education, Innovation Management, Organization Behavior \& Science and Technology Policy. He has thirteen articles published in recognized journals of Pakistan, India, Nigeria and USA. He has presented papers in four International Conferences held in Pakistan, respectively; He has experience of Session Chair in International Conference. He has attended several workshops and training. 